UDC 316.334 .2

LBC 60.561 .2

\title{
ECONOMY AND CULTURE: IS IT POSSIBLE TO DECODE THE ECONOMY? [Book Review: "Because We Decided So": Behavioral Economy of Belarus and its Decoding / K. V. Rudy [et al.] ; under the Scientific Ed. of K. V. Rudy. - Minsk : Zvezda, 2017. - 368 p.]
}

\author{
Nadezhda V. Dulina \\ Volgograd State University, Volgograd, Russian Federation \\ Darya V. Moiseeva \\ Volgograd State Technical University, Volgograd, Russian Federation
}

\begin{abstract}
Slowing economic growth, failures of a number of reforms, and rising social tensions are problems encountered in many countries. K.V. Rudy, assistant to the President of the Republic of Belarus for economic issues (2013-2016), brought together a number of leading scientists of the Republic of Belarus and attempted to analyze the failure of the economic policy implemented by him during his public service. As one of the main reasons that the reform of the Belarusian economy could not be carried out according to the planned plan, he calls the culture of Belarusians and offers his view on the cultural matrix of Belarus. The monograph also offers a solution to the identified problem through decoding the economy by changing the cultural matrix, which should proceed in three directions: economic, institutional and socio-logical. The authors see economic decoding in improving the investment climate in order to attract foreign investment; institutional decoding - in changing existing economic, social and innovative development institutions; socio-logical decoding - in using educational paternalism through improving the education system, socio-political transformation by means of nudge ("nudge") and the renewal of the political system, which implies a multi-party system. Discussing the experience of a particular country, the authors of the monograph touch on an important topic of studying the influence of culture on the economy. The history of research on the relationship between economy and culture is rich, but the materials of the postSoviet countries are of an isolated nature. The review discusses methodological issues that are fundamentally important in the organization of such research and substantiates the relevance of scientific analysis of this topic on the example of Russia.

Key words: behavioral economics, economy, culture, cultural matrix, cultural code, reforms, values.

Citation. Dulina N.V., Moiseeva D.V. Economy and Culture: is it Possible to Decode the Economy? [Book Review: "Because We Decided So": Behavioral Economy of Belarus and its Decoding / K. V. Rudy [et al.]; under the Scientific Ed. of K. V. Rudy. - Minsk : Zvezda, 2017. -368 p.]. Logos et Praxis, 2021, vol. 20, no. 1, pp. 118-125. (in Russian). DOI: https://doi.org/10.15688/lp.jvolsu.2021.1.13
\end{abstract}




\author{
ЭКОНОМИКА И КУЛЬТУРА: \\ ВОЗМОЖНО ЛИ РАСКОДИРОВАНИЕ ЭКОНОМИКИ? \\ [Рец. на кн.: «Потому что так решили мы»: поведенческая экономика Беларуси \\ и ее раскодирование / К. В. Рудый [и др.] ; под науч. ред. К. В. Рудого. - \\ Минск : Звезда, 2017. - 368 с.] \\ Надежда Васильевна Дулина
}

Волгоградский государственный университет, г. Волгоград, Российская Федерация

Дарья Викторовна Моисеева

Волгоградский государственный технический университет, г. Волгоград, Российская Федерация

\begin{abstract}
Аннотация. Замедление экономического роста, неудачи ряда реформ, рост социальной напряженности - проблемы, встречающиеся во многих странах. К.В. Рудый - помощник Президента Республики Беларусь по экономическим вопросам (2013-2016 гг.), объединив ряд ведущих ученых Республики Беларусь, предпринял попытку анализа провала экономической политики, реализуемой им во время своей государственной службы. В качестве одной из главных причин того, что реформирование белорусской экономики не удалось провести по задуманному плану, он называет культуру белорусов и предлагает свой взгляд на культурную матрицу Беларуси. Также в монографии предлагается решение выявленной проблемы через раскодирование экономики путем изменения культурной матрицы, которое должно происходить в трех направлениях: экономическом, институциональном и социологическом. Экономическое раскодирование авторы видят в улучшении инвестиционного климата с целью привлечения иностранных инвестиций; институциональное раскодирование - в изменении существующих экономических, социальных институтов и институтов инновационного развития; социологическое раскодирование - в использовании просветительного патернализма через совершенствование системы образования, общественно-политическое трансформирование посредством подталкивания («nudge») и обновления политической системы, предполагающее многопартийность. Обсуждая опыт конкретной страны, авторы монографии затрагивают важную тему изучения влияния культуры на экономику. История изучения взаимосвязей экономики и культуры богата, но исследования на материалах стран постсоветского пространства носят единичный характер. В рецензии обсуждаются принципиально важные при организации подобных исследований методологические вопросы и обосновывается актуальность научного анализа обозначенной темы на примере России.

Ключевые слова: поведенческая экономика, экономика, культура, культурная матрица, культурный код, реформы, ценности.

Цитирование. Дулина Н. В., Моисеева Д. В. Экономика и культура: возможно ли раскодирование экономики? [Рец. на кн.: «Потому что так решили мы»: поведенческая экономика Беларуси и ее раскодирование / К. В. Рудый [и др.] ; под науч. ред. К. В. Рудого. - Минск : Звезда, 2017. 368 с.] // Logos et Praxis. - 2021. - Т. 20, № 1. -C. 118-125. - DOI: https://doi.org/10.15688/lp.jvolsu.2021.1.13
\end{abstract}

Исследование взаимосвязей культуры и экономики имеет богатую научную традицию. Представители различных научных дисциплин ставят вопросы о влиянии культуры на развитие экономики, о влиянии экономики на формирование культуры, о взаимосвязи культурных ценностей населения страны и темпов ее экономического развития (М. Вебер, Т. Веблен, М. Грановеттер, К. Маркс, В. И. Ленин, Ф. Хайек и др.). Угол зрения при изучении обозначенной проблематики во многом опре- деляется той научной дисциплиной, в рамках которой работает ученый, что исходно ограничивает получаемый результат. Социологи упускают из виду экономические показатели, экономисты, наоборот, делают акцент на экономическом результате, не всегда оценивая социальные риски принимаемых экономических решений. В данной статье мы хотели бы обсудить основные идеи, изложенные в коллективной монографии «"Потому что так решили мы”: поведенческая экономика Беларуси 
и ее раскодирование», которая представляет собой междисциплинарную работу белорусских экономистов, социологов, историков и юристов по изучению влияния культурной матрицы на экономику Беларуси. На наш взгляд, несмотря на дискуссионность полученных результатов, книга заслуживает внимания и может служить ценным источником для рассуждения о том, какие ценности, разделяемые россиянами, способствуют, а какие препятствуют успешному экономическому развитию нашей страны.

Научным редактором и автором идеи создания книги стал белорусский государственный деятель, дипломат, доктор экономических наук, профессор Кирилл Валентинович Рудый (1978 г. р.). Полагаем важным обратить внимание на тот факт, что его карьерные передвижения тесно связаны с решением проблем, представленных в обсуждаемой монографии. В 2007-2012 гг. он был советником по торгово-экономическим вопросам Посольства Республики Беларусь в Китайской Народной Республике, в 2013-2016 гг. - помощником Президента Республики Беларусь по экономическим вопросам, в 2014-2016 гг. - начальником Главного экономического управления Администрации Президента Республики Беларусь, а с августа 2016 г. по январь 2020 г. Чрезвычайным и Полномочным Послом Республики Беларусь в КНР. Затем, изменив свою карьерную траекторию, он покинул государственную службу и ушел в бизнес. Занимая руководящие посты, К.В. Рудый во многом определял экономическую политику страны, и именно анализу текущей ситуации и складывающихся долгосрочных тенденций в национальной экономике Республики Беларусь была посвящена другая его монография «Финансовая диета: реформы государственных финансов Беларуси» [Финансовая диета... 2016]. По сути, в упомянутой монографии представлены основные положения реализуемой политики в области государственных финансов в период его руководства, а монография «Потому что так решили мы» - это анализ проделанной работы. Как пишет сам К.В. Рудый, «"Потому что так решили мы” - это продолжение “Финансовой диеты”, “Заключение” в которой оказалось “Введением” для этой книги. Продолжать заставила очевидность сложившихся в той книге заблуждений <...> Все эти заблуждения заставили расширить взгляд и посмотреть на белорусскую экономику не только с точки зрения экономиста. Также и перед белорусским читателем открывается возможность под другим углом взглянуть на себя и свое экономическое поведение» [«Потому что так решили мы»... 2017, 16-17]. К.В. Рудый, пытаясь найти причину неудач предложенных им преобразований, обратился к изучению белорусского менталитета и поведенческой модели белорусов в экономике.

Надо отметить, что монография вызвала волну негативной реакции среди белорусских ученых [Борнукова, Годес, Щерба 2020; Воробьев, Майборода 2017; Долинина 2017; Злотников 2018]. Линия критики пролегает как в теоретическом, так и в идеологическом русле. При этом в основном критика адресована непосредственно научному редактору, что вполне может объясняться непопулярностью тех мер финансовой политики, которые были реализованы К.В. Рудым. Не будем погружаться в идеологические споры, а обратимся к конструктивной части критики. Так, например, А.Г. Злотников, В.А. Воробьев и Т. Л. Майборода отмечают, что научный редактор монографии К.В. Рудый чрезмерно вольно перерабатывает теоретические основания, заложенные в новой поведенческой экономике Р. Талера, которая обозначена как основной методологический ресурс. Итак, постараемся представить основные идеи книги.

Первая глава монографии «Культурная матрица: немного теории и практики» построена на богатой библиографии и содержит анализ использования термина «культурная матрица» в разных науках (нейронауке, психологии, социологии, социальной психологии, культурологии, этнологии, антропологии, политологии, экономике и математике). В итоге К.В. Рудый дает собственное определение: «культурная матрица представляет собой сложную, открытую, гибкую и динамичную систему ценностей, определяющих национальные черты» и отмечает, что «национальная матрица складывается под влиянием многообразия природно-географических, исторических, культурных, религиозных, расовых, возрастных, лингвистических, политических, экономических и 
иных факторов [«Потому что так решили мы»... 2017, 32-33]. Далее по тексту он уточняет: «Включая в себя совокупность ценностей, поведенческих практик, стереотипов и т. п., культурная матрица в каком-то смысле может рассматриваться как нечто в целом иррациональное, бессознательное и неустойчивое, что можно изменить» [«Потому что так решили мы»... 2017, 35]. Дополняя содержание культурной матрицы, К. В. Рудый, по сути, расширяет это понятие до понятия культуры в социологическом ее измерении: «культура это совокупность материальных и духовных ценностей, выражающая определенный уровень исторического развития данного общества и человека» [Социологический энциклопедический словарь 1998, 151]. Возникает вопрос: так чем же культурная матрица отличается от культуры в целом? Тем, что она определяет национальные черты? Каков критерий выделения тех ценностей, которые их определяют, а которые нет?

Надо отметить предельную честность К.В. Рудого, который, предваряя критику оппонентов (например: [Тамбовцев 2015]), задается вопросом: а есть ли вообще культурная матрица? И ответу посвящает целый параграф. Интересен вывод, сделанный им: «Таким образом, вопрос, есть ли вообще культурная матрица, обоснован и уместен в рамках данного исследования. Он важен сам по себе для понимания относительности, несовершенства и неуниверсальности отдельных культурных матриц. Этот вопрос подтверждает важную идею данной книги: отдельная национальная культурная матрица не может претендовать на истину, она служит лишь инструментом ее познания» [«Потому что так решили мы»... 2017, 38]. По нашему мнению, автор несколько смешивает уровни познания: культурная матрица - это исследовательский инструмент, необходимый для понимания основ функционирования общества в целом и экономики в частности, и ставить вопрос о его существовании в другом контексте не вполне корректно. Размышляя над книгой, нам представляется важным поставить вопрос о существовании ценностей, которые способствуют или препятствую развитию экономики страны.

Определившись с понятием культурной матрицы, К.В. Рудый представляет свой лич- ный взгляд на белорусскую культурную матрицу: «В рамках данного исследования главными чертами современной белорусской матрицы, которые будут далее эмпирически обоснованы, более подробно рассмотрены в своем влиянии на экономику и подвергнуты раскодированию, являются двоемыслие, ориентация на советское прошлое и патернализм» [«Потому что так решили мы»... 2017, 46]. Автор логическим путем сформулировал основные характеристики культурной матрицы Беларуси. Еще раз повторимся, что наша рецензия в большей степени ставит вопрос о возможности использования предложенного подхода к анализу влияния культуры и экономики, чем направлена на обсуждение полученных результатов. С этих позиций автор ставит правильный методические вопросы: возможно ли изучение культурной матрицы изнутри или оно будет искажено и необходим внешний взгляд, при этом не будет ли внешняя оценка - «взгляд из другой культурной матрицы» - так же искажен? Требует ли изучение культурных матриц межстранового сравнения? Еще один важный методический вопрос: что первично культура или экономика? Автор в решении этого вопроса прямолинеен: «экономика может и является лишь частью нашей жизни, но определяющей частью» [«Потому что так решили мы»... 2017, 56]. Думаем, подобные утверждения сильно сужают угол исследовательского зрения, тогда как для понимания экономической ситуации необходимо погружение экономики как объекта исследования в более широкий социокультурный контекст.

Обозначив методологическую рамку изучения культурной матрицы вообще и Беларуси в частности, авторы приступают к более тщательному ее представлению. Как отмечает К.В. Рудый, «Исследование культурной матрицы и ее влияния на экономику проводиться с двух сторон. С одной стороны экспертная оценка. Мнение, основанное на теории, белорусской и международной практике, исторических примерах, собственной оценке, впечатлениях, интуициях, личном опыте нахождения внутри и вне белорусской матрицы. С другой - социологический замер. Попытка разобраться в признаниях белорусов, их видении, приукрашивании, желаниях, стра- 
хах и лжи» [«Потому что так решили мы»... $2017,60]$. Таким образом, появляются две следующих главы: глава 2 «Поведенческая экономика Беларуси» и глава 3 «Социологическое измерение белорусских кодов». Глава 2 содержит экономические характеристики белорусов и факторы поведенческой экономики Беларуси. Эта часть книги, видимо, и вызвала негативную реакцию белорусских ученых. Здесь хотелось бы поставить вопрос о возможности употребления словосочетания «Поведенческая экономика Беларуси».

Поведенческая экономика - сравнительно новое направление экономических исследований, родившееся как попытка психологов объяснить несостоятельность экономических моделей, построенных на рациональности экономических объектов [Тайлер 2017]. Как научное направление методически оно основывается на экспериментальных наблюдениях, опросах и полевых исследованиях. Исследователей не интересует принадлежность к той или иной культурной матрице, они, основываясь на поведенческих экспериментах, изучают экономическую нерациональность агентов и предлагают модели, ее описывающие. Поведенческой экономикой можно назвать модель управления экономикой страны, где широко используются стратегии «nudge» [Талер, Санстейн 2018]. Заголовок второй главы не отражает ее содержание, возможно, уместнее было бы дать стандартный анализ экономических показателей страны, выделив наиболее слабые стороны, или результаты поведенческих экспериментов, которые бы наглядно доказывали, что белорусы ведут себя иначе. И еще один важный момент: поведенческая экономика - это не про ценности и культурные матрицы, но и психология принятия экономических решений.

Глава 3, по задумке научного редактора, должна содержать социологический замер культурной матрицы, однако без логичного перехода начинается анализ культурного, экономического и финансового кодов Беларуси. За рамками монографии остается соотнесение понятий «культурная матрица» и «культурный (экономический, финансовый) код». Первый параграф третьей главы построен по логике, отличной от изложения предыдущей части книги: вводится понятие «цивилизацион- но-культурный код», представляется концепция его исследования [«Потому что так решили мы»... 2017, 110] и результаты выполненного в 2016 г. социологического исследования. Белорусские социологи, подготовившие данную главу, последовательно представляют структуру базовых ценностей белорусского общества, социологическое измерение отношения белорусов к таким ценностям, как работа, деньги, равенство, частная собственность, конкуренция, инновации, а также оценку практик и мотивов финансового поведения. Они приходят к выводу, что «в экономическом коде Беларуси можно выделить как ориентиры на рыночную экономику, так и культурные барьеры для ее развития» [«Потому что так решили мы»... 2017, 120]. Ученые сдержаны в своих оценках и отмечают, что для подтверждения полученных ими выводов требуется мониторинг и межстрановое сравнение. Социологическое измерение экономического и финансового поведения белорусов выполнено грамотно и позволяет составить представление об изучаемых феноменах. Знакомство с текстом этого параграфа вызывает вопрос: а как обстоят дела в России? Каковы культурный, экономический и финансовый коды россиян? Поиск аналогичных исследований, реализованных на территории России, не увенчался успехом, единого комплексного исследования авторы рецензии не обнаружили, но есть ряд отдельных интересных замеров [ВЦИОМ 2020; Магун, Руднев 2019; Макарова, Фомичёва 2019].

Второй параграф третьей главы написан уже белорусскими экономистами и содержит описание представлений населения ряда стран (Беларусь, Россия, Польша) о наиболее значимых приоритетах развития страны (по данным исследований Всемирного обзора ценностей) в разные периоды (1989-1990 гг., 19951997 гг., 2011-2012 гг.), а также данные опроса населения Беларуси в 2014 г. В этом параграфе представлен анализ вероятных социальных проблем и рисков в Беларуси через 10-15 лет и перспектив белорусской экономики в 2030 г. Авторы отмечают, что у белорусов существует запрос не только на изменение бизнес-климата, но и на изменение культурной матрицы. Они считают, что эволюционных изменений культурной матрицы можно 
ждать очень долго, необходимо повышение скорости раскодирования экономики Беларуси через культурную, социальную и экономическую открытость: «Только открытость трансформирует национальную матрицу и ее влияние на экономику» [«Потому что так решили мы»... $2017,152]$. Таким образом, если в первом параграфе авторы ставили вопрос и о наличии самой культурной матрицы и об ее влиянии на экономику, то в середине книги они снимают эти вопросы, дав положительный ответ на вопрос о ее существовании, и начинают предлагать решения по раскодированию экономики и изменению культурной матрицы белорусов.

По мнению авторов монографии, раскодирование или изменение культурной матрицы должно происходить в трех направлениях: экономическом, институциональном и социологическом. Суть экономического раскодирования - это улучшение инвестиционного климата с целью привлечения иностранных инвестиций. Институциональное раскодирование заключается в изменении существующих экономических, социальных институтов и институтов инновационного развития с целью повышения доверия к ним. Под социологическим раскодированием авторы понимают использование просветительного патернализма через совершенствование системы образования, общественно-политическое трансформирование посредством подталкивания («nudge») и обновления политической системы, предполагающее многопартийность. «Рецепты лечения» давно знакомы, сложности возникают на этапе реализации их в реальной жизни.

Интересна последняя глава монографии «Раскодированная экономика Беларуси», в которой представлена футуристическая картина будущего Беларуси глазами научного редактора монографии. В свободной форме К.В. Рудый представляет читателю то, как будет выглядеть будущее и что необходимо сделать, чтобы быть максимально готовым к грядущим изменениям. Не будем давать оценочных суждений нарисованной картине, важно, что она есть, есть некое видение направления развития, анализ которого тоже может стать ценным источником для будущих научных исследований.

В заключение хотелось бы вернуться к исходному вопросу, который мы поставили: воз- можно ли раскодирование экономики? Наш ответ однозначен: возможно, и возможно именно на основе понимания экономики через те ценности, которые разделяет и воспроизводит конкретное общество. Книга, на которую написана данная рецензия, может, и не является самым удачным примером исследования, направленного на изучение взаимосвязи экономики и культуры; не в полной мере научному редактору удалось организовать действительно междисциплинарное исследование, но анализ чужих ошибок порой может стать ценным источником новых исследований, лишенных части недостатков предыдущих. Закончить бы хотелось цитатой из работы Ш. Бёгельсдейка и Р. Маселанд «Культура в экономической науке: история, методологические рассуждения и области практического применения в современности»: «Мы видим, как экономисты постепенно уходят от откровенно узких интерпретаций в рамках методологического индивидуализма и проявляют все больший интерес к социальному взаимодействию и межсубъектным смыслам и убеждениям. Мы верим, что эти изменения могут придать экономической науке новые силы и сделать область исследований культуры в экономике критически важным направлением работы в грядущие десятилетия» [Бёгельсдейк, Маселанд 2016, 382-383]. Можно лишь присоединиться к высказанному выше тезису, признавая, что наиболее важные открытия, объясняющие экономическое поведение, лежат на стыке нескольких научных дисциплин, но в первую очередь все-таки экономики и социологии.

\section{СПИСОК ИСТОЧНИКОВ}

Бёгельсдейк, Маселанд 2016 - Бёгельсдейк Ш., Маселанд Р. Культура в экономической науке: история, методологические рассуждения и области практического применения в современности / пер. с англ. Н.В. Автономовой; науч. ред. В.С. Автономов. М.; СПб.: Изд-во Ин-та Гайдара; Изд-во «Международные отношения»; Факультет свободных искусств и наук СПбГУ. 464 c.

Борнукова, Годес, Щерба 2020 - Борнукова К., Годес Н., Щерба Е. Доверие в экономике: что это, как работает и для чего нужно? // Банковский вестник. № 3. С. 95-99. 
ВЦИОМ web - ВЦИОМ, 2000. Здоровье, семья и безопасность // https://wciom.ru/index.php?id= 236\&uid $=10318$.

Воробьев, Майборода 2017 - Воробьев В.А., Майборода Т.Л. Либертарианский патернализм Р. Талера: основания, возможности, концептуальные провалы // Белорусский экономический журнал. № 4. С. 4-22.

Долинина 2017 - Долинина Т.Н. Беларусь в кругу сопредельных стран: институциональные основы национальной конкурентоспособности // Белорусский экономический журнал. № 4. С. 114-128.

Злотников 2018 - Злотников А.Г. От заблуждений «Финансовой диеты» к заблуждениям «Раскодирования» Беларуси // Вестник РУДН. Серия: Экономика. № 3. С. 347-359.

Магун, Руднев 2019 - Магун В.С., Руднев М.Г. Динамика базовых ценностей российского населения: 2006-2018 // Будущее социологического знания и вызовы социальных трансформаций (к 90-летию со дня рождения В.А. Ядова): Междунар. науч. конф. (Москва, 28-30 ноября 2019 г.): сб. материалов / отв. ред. М.К. Горшков; ФНИСЦ РАН. М.: ФНИСЦРАН. С. 651-653.

Макарова, Фомичёва 2019- Макарова И.В., Фомичёва Л.М. К вопросу о роли культуры в развитии экономики // Самоуправление. Т. 2, № 1 (114). C. 91-94.

«Потому что так решили мы»: поведенческая экономика Беларуси и ее раскодирование: монография, 2017 / К.В. Рудый [и др.]; под науч. ред. К.В. Рудого. Минск: Звезда. 368 с.

Социологический энциклопедический словарь 1998. Редактор-координатор - академик РАН Г.В. Осипов. М.: ИНФРА-М, 1998. 488 с.

Тайлер 2017 - Тайлер Р. Новая поведенческая экономика. Почему люди нарушают правила традиционной экономики и как на этом заработать М.: Эксмо. 368 с.

Талер, Санстейн 2018 - Талер Р., Санстейн К. Nudge. Архитектура выбора. М.: Манн: Иванов и Фербер. 240 с.

Тамбовцев 2015 - Тамбовцев В.Л. Миф о «культурном коде» в экономических исследованиях // Вопросы экономики. № 12. C. 85-106. https:// doi.org/10.32609/0042-8736-2015-12-85-106.

Финансовая диета... 2016 - Финансовая диета: реформы государственных финансов Беларуси: монография / К.В. Рудый [и др.]; под ред. К.В. Рудого. Минск: Звезда. 464 с.

\section{REFERENCES}

Begelsdijk S., Maseland R., 2016. Culture in economic science: history, methodological reasoning and areas of practical application in modern times. Trans. N.V. Avtonomova; V.S. Avtonomov (ed.). Moscow, Izd-vo In-ta Gajdara; Izd-vo «Mezhdunarodnye otnosheniya»; Fakul'tet svobodnyh iskusstv i nauk SPbGU. 464 p.

Borukova K., Godes N., Shcherba E., 2020. Trust in the economy: what is it, how does it work, and what is it for? Bankovskij vestnik, no. 3, pp. 95-99.

VCIOM, 2020. Health, family, and safety. URL: https:/ /wciom.ru/index.php?id=236\&uid=10318.

Vorobyov V.A., Mayboroda T.L., 2017. R. Thaler's Libertarian Paternalism: Foundations, Opportunities, and Conceptual Failures. Belorusskij ekonomicheskij zhurnal, no. 4, pp. 4-22.

Dolinina T.N., 2017. Belarus in the circle of neighboring countries: institutional foundations of national competitiveness. Belorusskij ekonomicheskij zhurnal, no. 4, pp. 114-128.

Zlotnikov A.G., 2018. From the delusions of the "Financial Diet" to the delusions of the" Decoding " of Belarus. Vestnik RUDN. Seriya: Ekonomika, no. 3, pp. 347-359.

Magun V.S., Rudnev M.G., 2019. Dynamics of basic values of the Russian population: 2006-2018. Budushchee sociologicheskogo znaniya $i$ vyzovy social'nyh transformacij (k 90-letiyu so dnya rozhdeniya V.A. Yadova): Mezhdunar. nauch. konf. (Moskva, 28-30 noyabrya 2019 g.): sb. materialov. Gorshkov M.K. (ed.); FNISC RAN. Moscow, FNIC wounds, pp. 651-653.

Makarova I.V., Fomicheva L.M., 2019. On the question of the role of culture in the development of the economy. Samoupravlenie, vol. 2, no. 1 (114), pp. 91-94.

"Because we decided so": behavioral economy of Belarus and its decoding: monograph, 2017. K.V. Rudy [et al.]; RudyK.V. (ed.). Minsk, Zvezda Publ. 368 p.

Sociological encyclopedic dictionary. Osipov G.V. (ed.). Moscow, INFRA-M, 1998. 488 p.

Tyler R., 2017. The new behavioral economy. Why do people break the rules of the traditional economy and how to make money on it? $368 \mathrm{p}$.

Thaler R., Sunstein K., 2018. Nudge. Architecture of choice. Moscow, Mann, Ivanov and Ferber. $240 \mathrm{p}$.

Tambovtsev V.L., 2015. The myth of the "cultural code" in economic research. Voprosy ekonomiki, no. 12,pp. 85-106. URL: https://doi.org/10.32609/ 0042-8736-2015-12-85-106.

Financial diet: reforms of the state finances of Belarus, 2016. K.V. Rudy [et al.]; Rudy K.V. (ed.). Minsk, Zvezda Publ. 464 p. 
Н.В. Дулина, Д.В. Моисеева. Экономика и культура: возможно ли раскодирование экономики?

\section{Information About the Authors}

Nadezhda V. Dulina, Doctor of Sciences (Sociology), Professor, Department of Sociology, Volgograd State University, Prosp. Universitetsky, 100, 400062 Volgograd, Russian Federation, nv-dulina@volsu.ru, https://orcid.org/0000-0002-6471-7073

Darya V. Moiseeva, Candidate of Sciences (Sociology), Associate Professor, Department of Management and Finance of Production Systems and Technological Entrepreneurship, Volgograd State Technical University, Prosp. Lenina, 28, 400005 Volgograd, Russian Federation, moiseeva-d@yandex.ru, https://orcid.org/0000-0003-2044-3418

\section{Информация об авторах}

Надежда Васильевна Дулина, доктор социологических наук, профессор кафедры социологии, Волгоградский государственный университет, просп. Университетский, 100, 400062 г. Волгоград, Российская Федерация, nv-dulina@volsu.ru, https://orcid.org/0000-0002-6471-7073

Дарья Викторовна Моисеева, кандидат социологических наук, доцент кафедры менеджмента и финансов производственных систем и технологического предпринимательства, Волгоградский государственный технический университет, просп. Ленина, 28, 400005 г. Волгоград, Российская Федерация, moiseeva-d@yandex.ru, https://orcid.org/0000-0003-2044-3418 